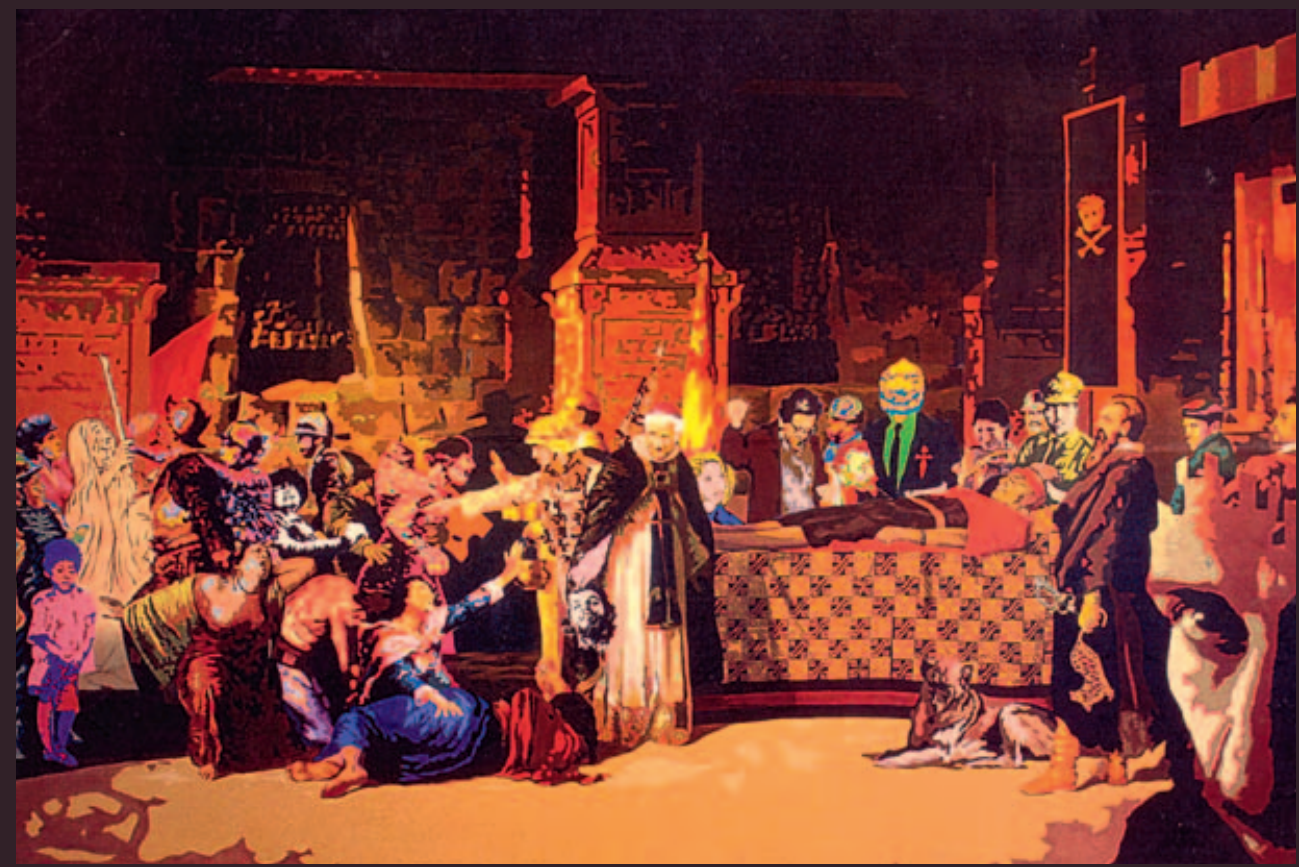

Funerales de Atahualpa. Marcel Velaochaga, 2006. Serigrafía. 


\section{Los funerales de Atahualpa y el imaginario histórico peruano ${ }^{1}$}

Nanda Leonardini

La pintura histórica nacional en el Perú se comienza a realizar, en pequeña escala desde el inicio del ochocientos, considerando dentro de este asunto a las alegorías de la Patria. Uno de los primeros artistas en cubrir dicho género es el piurano Luis Montero ${ }^{2}$ con un enorme lienzo conocido como Los funerales de Atahualpa, ${ }^{3}$ cuyas dimensiones siguen a los óleos que respondían "al patrón de las grandes máquinas pictóricas europeas." ${ }^{4}$

Para poder comprender el momento que Montero plasma, el choque cultural habido en noviembre de 1532, es necesario remitirse a la época cuando los españoles, encabezados por Francisco Pizarro, arriban al Perú, más específicamente a Cajamarca donde el Inca Atahualpa ${ }^{5}$ no había tomado en cuenta a ese grupo de aventureros que mal vestidos habían pisado las costas desde hacía algún tiempo. ${ }^{6}$ La tarde del día 16 del citado mes el Inca es tomado prisionero cuando llega a la plaza sentado sobre su trono de oro. Para conseguir su libertad ofreció un rescate fabuloso:

... llenar dos veces de plata y una de oro el cuarto de su prisión hasta la altura que señalaba con su brazo levantado (casi 2 metros de altura) ${ }^{7}$. El compromiso fue aceptado por los españoles. Pero no cumplieron. Conseguido el Rescate, lo mataron (un año después de su captura) bajo pretexto de estar organizando secretamente sus ejércitos.

1 El presente trabajo ha sido factible gracias a los comentarios y sugerencias de las siguientes personas, a quienes les expreso mi más sincero agradecimiento: por sus comentarios y sugerencias: Artista Marcel Velaochaga, Arqueólogo Manuel Aguirre-Morales, Doctor Jorge Coli, Bachiller Judith León, Licenciada Cecilia Linares, Licenciada Isabel Palomino; por algunas imágenes: Licenciada Giselle Castillo Hernández, Doctor Jorge Coli, Magister Leopoldo Lituma, Licenciada Sabrina Pizarro.

2 Nace en Piura en 1825. Becado por el gobierno, marcha a Florencia donde estudia en la Academia de dicha ciudad. Pinta el primer desnudo peruano en 1851 bajo el nombre Venus dormida. Fallece en el Callao el 24 de marzo de 1869 a raíz de la epidemia del cólera.

3 Elaborado en Florencia entre 1864 y 1867. Es un óleo sobre tela que mide 420 x $600 \mathrm{~cm}$. En la actualidad está ubicado en el Museo de Arte de Lima.

4 Amigo 2001:13.

5 Nace en Cusco, se estima que en 1500. Muere asesinado en Cajamarca el 29 de agosto de 1533. Su nombre significa "luchador victorioso". Hijo de Huayna Capac y de Tocto Coca, al arribo de los españoles al Perú se encontraba en guerra con su hermano Huáscar con quien disputaba el derecho a gobernar el Tahuantinsuyo a raíz de la muerte de su padre. Le correspondía ser el XIII gobernante Inca y así es reconocido, junto a Huáscar, en los óleos coloniales que desarrollan la genealogía inca.

6 En setiembre de 1532 Francisco Pizarro marcha a la sierra con un ejército compuesto de una caballería de 67 más 110 hombres entre artilleros y soldados a pie. Macera s/f:36.

7 El rescate ascendió a 6087 kilos de oro y 11,793 kilos de plata. Los soldados a caballo recibieron 40 kilos de oro y 80 de plata; los peones 20 de oro y 40 de plata; los soldados con perros más que los peones; los sacerdotes la mitad de un peón: 10 de oro y 20 de plata. A Pizarro le tocó siete veces más que a un jinete a caballo: 280 kilos de oro y 560 de plata, además del trono de Atahualpa que pesaba 83 kilos de oro. Macera $\mathrm{s} / \mathrm{f}: 36$. 


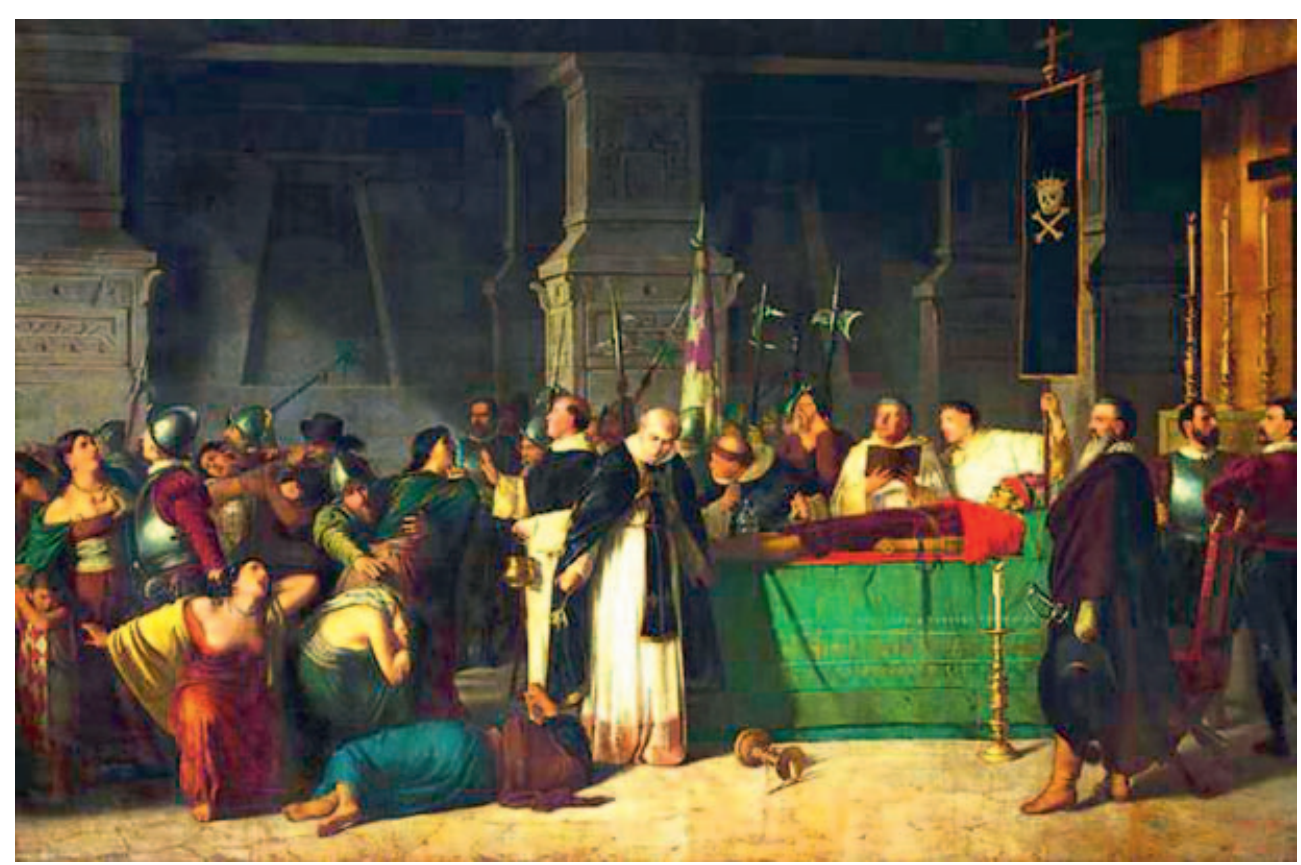

Los funerales de Atahualpa. Luis Montero, 1867. Óleo sobre tela.

Los españoles amenazaron con quemar vivo al Inca. Para impedirlo (porque así desaparecía su alma según las creencias andinas), Atahualpa aceptó el bautismo. Le aplicaron entonces la pena de garrote y lo enterraron en Cajamarca. ${ }^{8}$

Como es conocido, en la primera mitad del siglo XIX el historiador William Prescott escribe sobre la conquista de México y Perú, textos que sirvieron a varios artistas para poder inspirarse en la composición de un cuadro histórico. Montero no fue la excepción. Cuando Prescott en su libro Historia de la Conquista de Perú, publicado en 1847, se refiere a los funerales de Atahualpa, relata:

A la mañana siguiente le trasladaron a la Iglesia de San Francisco, ${ }^{9}$ donde se celebraron sus exequias con gran solemnidad. Pizarro y los principales caballeros asistieron de luto, y las tropas escucharon con devota atención el oficio de los difuntos, que celebró el padre Valverde. Interrumpieron la ceremonia muchos gritos y sollozos que se oyeron a las puertas de la Iglesia, las cuales abriéndose de repente, dieron entrada a un gran número de indias esposas y hermanas del difunto, que invadieron la gran nave, rodearon al cuerpo diciendo, que no era aquel el modo de celebrar los funerales de un Inca, y declaran su intención de sacrificarse sobre su tumba y acompañar al país de los espíritus. Los circunstantes ofendidos de ese loco proceder manifestaron a los invasores que Atahualpa había muerto cristiano, y que el Dios de los cristianos aborrecía de tales sacrificios. Después las intimaron que se salieran de la Iglesia, y muchas de ellas al retirarse se suicidaron con la vana esperanza de acompañar a su amado señor en las brillantes mansiones del Sol. ${ }^{10}$

8 Macera s/f:36.

9 Prescott no se ajusta a la verdad. Los franciscanos llegaron a Cajamarca en 1549 iniciando la construcción de su monasterio (Silva Santiesteban 1987:9). Por otra parte, Pizarro venía acompañado del clero dominico.

10 Tomado de Amigo 2001:17. 
Una vez más los textos influyen sobre la pintura. Este hecho editorial en cierta medida coincide con el poema del húngaro Gergely Czuczor escrito diez años antes, dedicado a la muerte del temido enemigo de los turcos, el héroe János Hunyadi ${ }^{11}$, poesía que inspira a la pintura histórica The Death of János Hunyadi ${ }^{12}$ elaborada por el artista húngaro József Schmidt aproximadamente en 1837 . Schmidt improvisa la cama del patriota János Hunyadi en el interior de una iglesia barroca delante de un altar del mismo estilo, quien llama a sus descendientes a continuar la lucha.

En el cuadro Los funerales de Atahualpa de Luis Montero la ceremonia luctuosa se realiza en el interior de un inmueble inca de piedra adaptado a las necesidades cristianas, tal como los españoles lo habían hecho con las mezquitas en la península Ibérica. En él se ven los vanos trapezoidales, aunque los pilares, con sobrerrelieves geométricos emulando las decoraciones incaicas, son una interpretación neo indigenista del autor, válida para el romanticismo.

Sobre esta obra se ha hablado en reiteradas ocasiones dentro del arte peruano, por lo que no es nuestro interés repetir ideas. ${ }^{13}$ Nos detendremos en lo elaborado por el historiador de arte Alfonso Castrillón Vizcarra quien comenta que "el cuadro está divido por una columna que quiere resaltar dos partes diferentes.” Más adelante continúa:

Frente al dinamismo de la izquierda, llama la atención la horizontalidad que se advierte en el derecho. Las mujeres del Inca luchan por acercarse a su cadáver, pero los soldados se lo impiden; también los curas que hacen eje con la columna. La diferenciación de los dos mundos está planteada: el nativo, reprimido (de rodillas o tendido) se ha quebrado como el candelabro del primer plano; lo español, de pie, hierático, inconmovible. Pizarro mira el futuro, mientras el Inca ha desaparecido para siempre. ${ }^{14}$

De un total de $31^{15}$ personas que forman parte del conjunto, 23 son españoles y ocho indios. Siguiendo el mismo planteamiento compositivo de Schmidt, a la izquierda Montero agrupó, con la bandera real hispana y un estandarte de la muerte sostenido por un fraile, a trece individuos, desde luego a los más importantes, los actores principales entre los que destaca el Inca Atahualpa, Francisco Pizarro, el sacerdote fray Vicente Valverde ${ }^{16} \mathrm{y}$, probablemente, Hernando Pizarro, Melchor Verdugo ${ }^{17}$ y Diego de Almagro. ${ }^{18}$ Suman doce hispanos de pie, quienes simbolizan el poder eclesiástico en cuatro de ellos a través de la orden dominica que acompaña la empresa capitalista de la conquista y ocho militares representativos del poder militar, todos en torno al lecho donde el Inca, símbolo mudo del pueblo indígena, sobre un lujoso manto verde yace inerte aún con las cadenas en su muñeca, mensaje subliminal del sojuzgamiento al que ingresaba el Perú bajo el dominio de una corona ajena a su entorno. Es decir, el pueblo sucumbido por poderes eclesiásticos y militares extranjeros, donde ni la misma muerte de Atahualpa ha servido para liberarlo, pues éste para alcanzar dignidad ante ella debió someterse al sacramento del bautismo. ¿Es acaso ésta la primera manifestación de sincretismo religioso en tierras peruanas?, o como

11 János Hunyadi (1387-1456). Elegido gobernador de “Transilvania y capitán de Belgrado (1440), rechazó una invasión de los turcos.” Enciclopedia Salvat 1984:1745.

12 Óleo sobre tela, $60 \times 75 \mathrm{~cm}$., Budapest, Colección privada.

13 Uno de los más importantes es Roberto Miro Quesada.

14 Castrillón 1994:92-93.

15 Roberto Amigo en su estudio Tras un Inca señala 36 personas. Por su parte Gabriela Lavarello de Velaochaga en su libro Artistas Plásticos en el Perú afirma que son 33. En lo personal, contabilizo sólo a 31.

16 Valverde es quien, en medio de la Plaza de Cajamarca con la Biblia en la mano "comenzó a explicar al Emperador Andino las verdades de la fe cristiana" y ante el rechazo del Inca increpa a los españoles: “Cristiano, ¿qué esperan ustedes? Los evangelios están por tierra.” Macera s/f:35.

17 Sanguinario hombre, encomendero de Cajamarca desde 1533.

18 Se había reunido al grupo de conquistadores el 12 de abril de 1533. 
señala el antropólogo Manuel Marzal, ¿es por parte del indio la aceptación del catolicismo con ciertas reinterpretaciones, conservando muchos elementos religiosos autóctonos? ${ }^{19}$

Por otra parte, Montero, con este número trece ¿intentaría dar una lectura sobre la última cena de Cristo y la traición habida en ella, siendo en este caso la víctima del sacrificio Atahualpa? Es una forma de expresar la traición española cuando, después de recibir la recompensa equivalente a 6087 kilos de oro y 11,793 de plata, es decir las treinta monedas de Judas, dan pena de muerte al Inca bajo la excusa de que éste organizaba en secreto a su ejército. De esta manera Los funerales de Atahualpa sería, además de una obra histórica nacional, una fina crítica a España y al clero desde una perspectiva del pensamiento liberal del momento, aunque, como señala Castrillón, el indio estaba excluido.

Pero continuemos ahora con la izquierda de la obra donde hay 18 personas. Es una escena teatral en la cual los participantes no pueden entenderse no solo por problemas linguiísticos del castellano y latín frente al quechua, sino por abismales diferencias culturales donde la religión juega un rol trascendente; mientras los peninsulares, convencidos, venían a extirpar idolatrías en una cruzada santa medieval, las otras, porque todas son mujeres, reclaman sus derechos consanguíneos, sus rituales ancestrales, es decir defienden su propia identidad cultural. En este caso Montero, que se autorretrata al fondo en una figura en cierta medida ajena al hecho, presenta, imagino sin quererlo, un caso de género: la violencia masculina tan denunciada en la actualidad, frente a la femenina. Venidos de un sacerdote y diez soldados, golpes físicos, emocionales y morales sufren seis damas, coyas, hermanas, parientas que gritan, lloran compungidas, se suicidan, suplican, luchan o discuten, acompañadas de un asustado niño, protegido por una de ellas, quien viste un unku con los colores nacionales (rojiblanco). Es, con seguridad, uno de los descendientes de Atahualpa que mudo, cabizbajo, presencia impotente el hecho que significa la caída del Tahuantinsuyo y junto a ella su propio destino incierto; ¿es el destino mismo del Perú? Cabe preguntarse, según el relato de Prescott, el por qué los hombres indígenas no se atrevieron a interrumpir la ceremonia. ¿Existe acaso una imperceptible línea de continuidad con la actual idiosincrasia peruana donde la mujer saca la cara para defender a la familia y a la sociedad en los momentos coyunturales? O, simplemente, como señala el escritor Gabriel García Márquez, que son las mujeres "las que sostienen el mundo, mientras los hombres lo desordenamos con nuestra brutalidad histórica." ${ }^{20}$ Como el indio estaba excluido de los proyectos en la sociedad decimonónica peruana, Montero representa a las mujeres del inca empleando para ello hermosos modelos de italianas blancas, robustas, rollizas; desde luego el ideal académico de belleza.

Entre todos los personajes plasmados en la obra, a nuestro juicio destacan tres. La hermosa coya hincada que, como una Magdalena, grita desesperada. Sin lugar a dudas es la misma imagen, invertida, que el artista había empleado en su cuadro Matanza de los inocentes, esta vez defendiendo a su hijo del asesino que intenta degollarlo. El segundo es fray Vicente Valverde quien, semi girado, como eje hierático, divide la composición en las dos secciones ya señaladas; allí, ensimismado, ajeno al entorno, pues está en el plan de sentirse intermediario ante el ente divino, con un hisopo lanza agua bendita sobre el cuerpo de la suicida, casi en un acto exorcista, en un intento fallido de no identificarse. Finalmente, el

19 Marzal 1990:7.

20 García Márquez 2002:89.

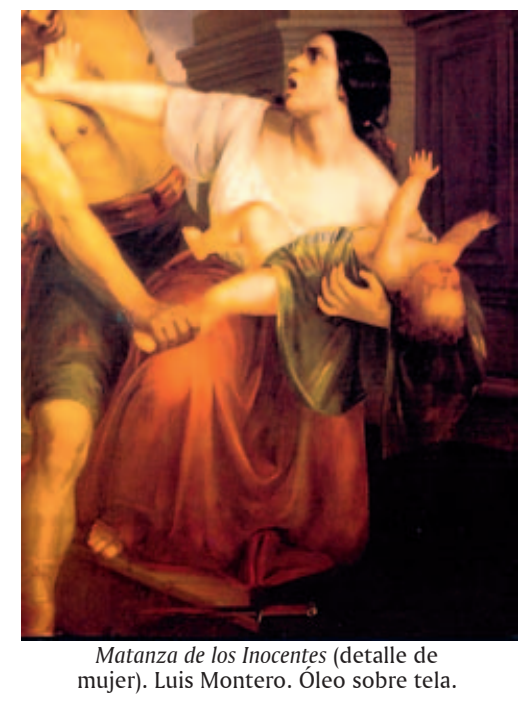


más importante: Atahualpa, el único indio; es sabido que Montero utilizó como modelo a su amigo Tinajero, un peruano que como él, vivía en Europa. ${ }^{21}$

El lienzo, iniciado en 1864 , es finalizado en 1867 después de escrupulosos estudios sobre la vida de los actores, retratos, vestuario, armamento, infinidad de dibujos y estudios. Este cuadro, que para Roberto Amigo "está dominado por el intento de reconstrucción verista que caracteriza a la pintura de historia a mediados del siglo XIX, sujeto a las pautas formales académicas", ${ }^{22}$ a nivel mundial y local tiene un éxito plástico jamás alcanzado con antelación en latinoamérica, no sólo por la cantidad de público que lo observó ${ }^{23}$ sino por el movimiento económico que generó, pues para apreciarlo en Buenos Aires se

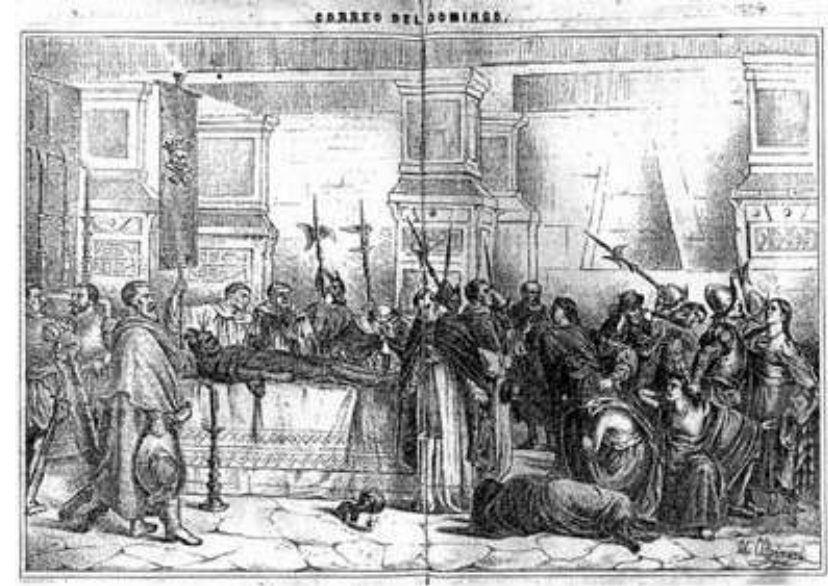

Los Funerales de Atahualpa. Luis Montero. Litografia de U Advinent. Publicada en Correo del Domingo.

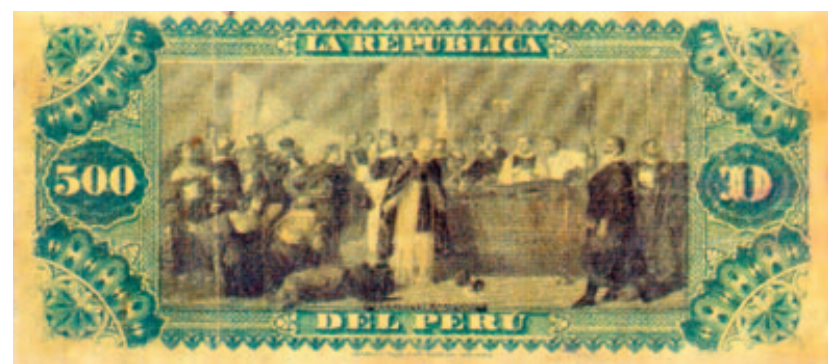

Los Funerales de Atahualpa. Luis Montero. Litografía para billete de 500 soles año de 1879.

debía pagar un boleto que ascendía a veinte dólares, ${ }^{24}$ por cierto nada de económico. Es en Argentina donde se elabora la primera reproducción en una litografía publicada en el Correo del Domingo en diciembre de ese año de $1867 .{ }^{25}$ Asimismo, Los funerales de Atahualpa habían recorrido otras capitales sudamericanas antes de llegar a Lima: Río de Janeiro y Montevideo, ${ }^{26}$ lo que produjo un revuelo periodístico desde Florencia al Perú, durante varios meses ${ }^{27}$ y que para Argentina significa "el primer debate artístico importante." 28

En junio de 1879, cuando el país se ve envuelto en la Guerra del Pacífico, ${ }^{29}$ el Banco La República del Perú emite un billete de 500 soles en cuyo reverso figura en grabado Los

21 Majluf 2004.

22 Amigo 2001:19.

23 En Lima el público alcanzó quince mil personas. Amigo 2001:21.

24 Amigo 2001:26.

25 Amigo 2001:13.

26 Se exhibió desde el 27 de noviembre de 1867 hasta el último fin de semana de febrero de 1868 . Amigo 2001:25.

27 En Florencia Il Corriere Italiano, Corriere de Firenze, L' Opinione y Gazzeta del Popolo publicaron artículos llenos "de halagos; en éste último, Bellini se había admirado del coraje de Luis Montero para acometer la obra que, por las dimensiones y por las exigencias históricas, difíciles de satisfacer, era ardua y costosa." (Laverello 2009). En Montevideo el periódico El Siglo se detuvo en ella. En Buenos Aires se ocuparon, a partir de setiembre de 1867 hasta diciembre del mismo año La Revista de Buenos Aires, La Nación Argentina, La Tribuna, The Standard and River Plate News, Correo del Domingo, El Nacional, Le Courrier de la Plata. Consultar el libro de Roberto Amigo Tras un inca. Los Funerales de Atahualpa de Luis Montero en Buenos Aires, donde hace un estudio acucioso del cuadro en Argentina. En el Perú en su momento lo trataron El Comercio, El Ateneo de Lima.

28 Amigo 2001:65.

29 (1879-1883). Conflicto bélico contra Chile que le significa al Perú la pérdida de gran parte del territorio nacional donde se encontraban innumerables recursos minerales. 
funerales de Atahualpa. A través de este billete la entidad bancaria nacional da un respaldo de identidad al país sumido en esta desagradable coyuntura internacional. Cuando el ejército invasor llega a la capital peruana (enero de 1881), se apropia del cuadro para remitirlo a Chile, junto a otros bienes culturales. Gracias a las gestiones realizadas por el escritor Ricardo Palma, ante el Presidente Domingo de Santa María, es devuelto en 1885; no resultaba casual este hurto que, como trofeo de guerra, encerraba identidad, historia y patrimonio cultural.

\section{Ciento cuarenta años después}

En el año 2005 el artista plástico Marcel Velaochaga, ${ }^{30}$ tomando como base este óleo, pero con un planteamiento postmoderno donde todo es factible, hace una reinterpretación actualizada, es decir los retratados forman parte de la historia del momento con un análisis crítico de la realidad nacional, de sus políticos, mártires y genocidas, si bien es cierto mantiene a ocho personajes concebidos en el cuadro del siglo XIX. ${ }^{31}$

La obra, bajo el mismo título, ${ }^{32}$ es expuesta por primera vez en Lima, en la muestra Revelaciones 2005-2006 ${ }^{33}$ y con posterioridad en la Bienal Sao Paulo-Valencia de 2007 donde es retirada, al parecer, por presiones de la Iglesia católica. ${ }^{34}$

Con la composición empleada por Montero, casi sin alternar el número de individuos, ${ }^{35}$ Velaochaga replantea el asunto histórico que ha marcado al Perú como uno de sus dos traumas más importantes. ${ }^{36}$ Para facilitar al lector, seguiremos la estructura de la primera parte de este texto. Es pertinente aclarar que las personas no son indios ni españoles, sino pueblo y fuerzas opresoras.

A la izquierda, ahora la bandera roji amarilla, empleada por el grupo subversivo Sendero Luminoso durante su guerra popular, reemplaza a la hispana real en tanto el estandarte de la muerte continúa vigente, esta vez colgado de la pared. Los trece personajes se entremezclan entre el pasado del siglo XVI y el del XXI, escogidos dentro de lo más graneado de cada época. Se mantienen, con pequeñas variantes, Atahualpa, Pizarro y un español hidalgo; al fraile Valverde le cambia la cabeza por la del Papa Benedicto XVI, mientras uno de los españoles hidalgo es modificado por un militar peruano que luce la bandera nacional en el antebrazo.

En torno al cadáver del Inca entran en escena nuevos individuos. Además

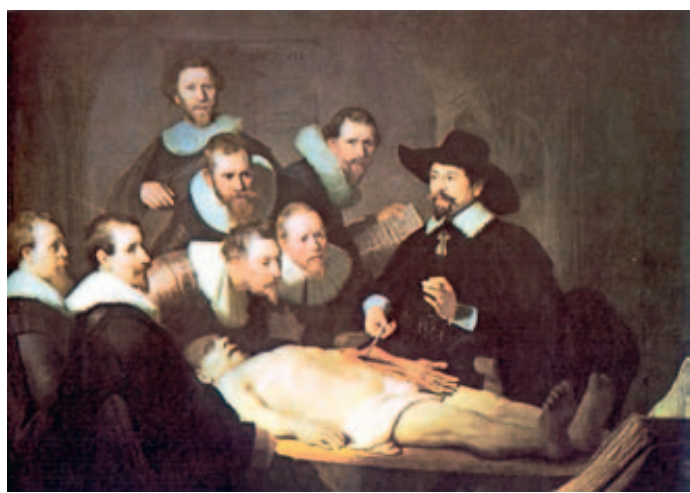

La lección de anatomía del Doctor Nicolaes Tulp. Rembrandt. Óleo sobre tela. 1632

30 Nace en Lima en 1969. Estudia en la Escuela Nacional de Bellas Artes. A partir de 1991 participa en proyectos que reflexionan sobre la historia contemporánea. Marcel Velaochaga [En línea]

31 Mantiene a Atahualpa, Pizarro, el español junto a Pizarro (a la derecha de la obra); un cura, a la mujer suicida, a la mujer que llora, al soldado que retiene a la mujer y al soldado que ahora discute con la anciana (a la izquierda).

32 Mide 300 x $450 \mathrm{~cm}$. Con posterioridad el artista sacó algunas reproducciones de menor tamaño en la técnica de la serigrafía.

33 Gustavo Buntinx fue el curador; allí “estableció un paralelo directo con el cuadro mismo. En esa muestra se logró incluso una museografía estrictamente simétrica colgando la (sub) versión de Velaochaga en el vano de una gran escalera ubicada frente a otra idéntica que en idéntica posición acoge desde hace años la obra gigantesca de Montero. Un juego de espejos pictóricos donde se puso en tensión la propia idea original y de la cita." Buntinx 2007.

34 Garvich 2007 [En línea].

35 Trece a la derecha y 17 a la izquierda.

36 Dos son los traumas históricos del Perú: la conquista hispana (1532) y la Guerra del Pacífico (1879-1883). 
de los militares, cuatro civiles; de derecha a izquierda son: de pie una india que mira compungida al Inca, imagen extraída de una fotografía de Juan Manuel Vilca publicada en el diario La República en 1983, durante los años de guerra interna. ${ }^{37}$ Un hombre, aparentemente sentado, observa con detenimiento científico el cuerpo de Atahualpa, figura proveniente del cuadro La lección de anatomía del Doctor Nicolaes Tulp de Rembrandt; es probable que Velaochaga con este individuo aluda a los antropólogos o arqueólogos forenses que levantaban los cadáveres de los entierros clandestinos entre los ochentas y noventas a lo largo y ancho de todo el Perú. Le sigue Abimael Guzmán, ideólogo y líder de Sendero Luminoso ${ }^{38}$ conocido como "Camarada o

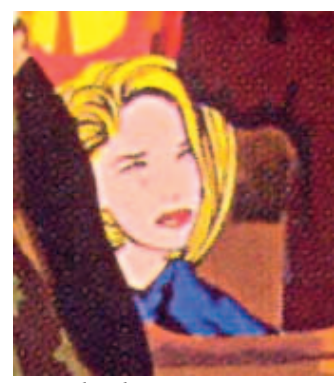

Velaochaga toma como referencia la imagen de Roy Lichtenstein. I am sorry. Presidente Gonzalo", en la difundida foto de 1985 cuando, junto al ataúd de la camarada Norah $^{39}$ levanta el brazo para despedirla, en un gesto representativo frente a la muerte..$^{40}$ Ahora bien, las tres imágenes provienen de momentos relacionados con la observación de un cadáver: el primero es un acto emotivo, el segundo uno científico y el tercero es político. Finalmente, la imagen de una mujer blanca norteamericana llorando, sacada de I am sorry, obra pop de Roy Lichtenstein. ¿Pretendía el artista aludir, a través de ella, a la emeterreista Lori Berenson ${ }^{41}$ quien por sus acciones es sentenciada a veinte años de prisión los cuales debe cumplir en el Perú a pesar de su nacionalidad estadounidense? Con esta adición, ¿quedarían así representadas las dos agrupaciones (Sendero Luminoso a través de su ideólogo y el Movimiento Revolucionario Tupac Amaru MRTA con Lori) que mantuvieron en sangriento jaque al país por más de una década?

De los militares sobresale el gigante vestido con camisa verde, corbata y terno negro en cuyo saco destaca, en rojo, la cruz de la orden de Santiago, nada casual, pues se trata de aquella orden militar que colaboró activamente en la reconquista española. ${ }^{42}$ Por otra parte este detalle de la cruz y la actitud de la figura mirando al espectador se encuentran en el autorretrato que Velázquez se hace

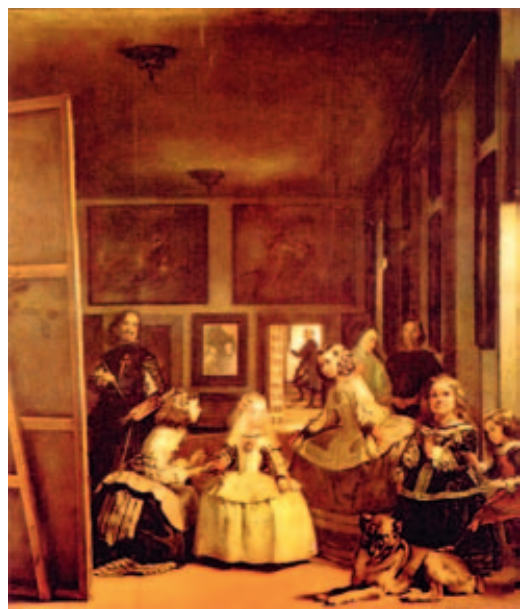

Diego Velázquez. Las Meninas. Óleo sobre tela.

37 "En Ayacucho, una mujer campesina acompaña el cuerpo de un familiar víctima del conflicto armado." (Yuyanapaq. Para recordar 2003:14).

38 Sendero Luminoso inicia sus acciones (a las que llama "guerra popular") el 17 de mayo de 1980 en el pequeño poblado de Chucchi, en la sierra ayacuchana.

39 Augusta La Torre Carrasco, camarada Norah, nace en Ayacucho en 1946; en 1962 conoce a Abimael Guzmán profesor de la Universidad San Cristóbal de Huamanga, con quien contrae matrimonio el 3 de febrero de 1964. Junto a Guzmán, comienza la guerra popular en 1980; es la número dos del Comité Permanente de Sendero Luminoso, encargado de tomar las decisiones y elaborar los planes estratégicos e ideológicos. Fallece sospechosamente el 14 de noviembre de 1984; enterrada en Lima, su cuerpo desaparece. (Velez 2004 [En línea]).

40 Existen diferentes versiones sobre la muerte de Norah en las cuales se habla de la participación de Guzmán y Miriam (la número 3 de Sendero Luminoso), debido a contradicciones ideológicas entre ellos. La tesis de Guzmán era un infarto, pero durante el velorio se contradice cuando asegura que ella se había suicidado. Para el grupo subversivo, Norah se convierte en heroína de la revolución. (Velez 2004 [En línea]).

41 Lori Berenson Kobeloff nace en Nueva York, Estados Unidos el 13 de noviembre de 1969. Joven emigra a El Salvador y con posterioridad al Perú donde se relaciona con el Movimiento Revolucionario Túpac Amaru (MRTA). El 30 de noviembre de 1995 es detenida con un comando del MRTA después que la policía descubre un plan del grupo para tomar rehenes en el Congreso con el fin de canjearlos por sus compañeros prisioneros. Es condenada a veinte años. (Lori Berenson [En línea]). Obtuvo libertad condicional en 2010.

42 La orden religiosa de Santiago nace en 1170 en España gracias al rey Fernando II de León y es aprobada en 1175 por el Papa. De carácter militar, colaboró con la reconquista española. 


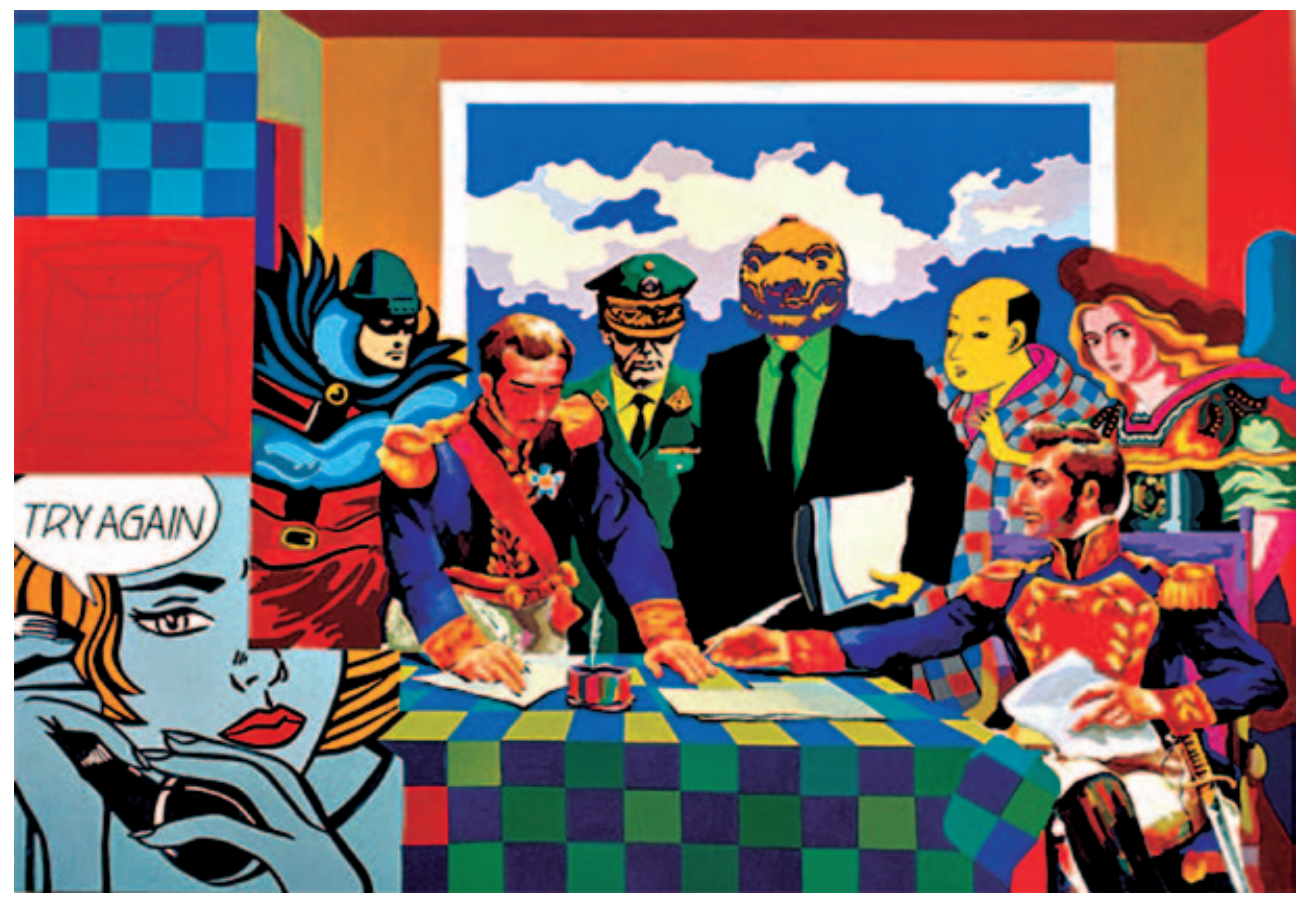

Try again. Marcel Velaochaga, 2002. Acrílico sobre tela. 150 x 200 cm. 2002.

en Las Meninas. Su colosal cabeza es la de un felino humanizado tomada de las clavas del horizonte Chavín (1800-500 a.C.). Sin lugar a dudas hace referencia al éxito de la operación Chavín de Huantar llevada a efecto el 22 de abril de 1997 para rescatar a los rehenes quienes, desde el 17 de diciembre del año anterior, permanecían capturados en la casa del embajador japonés por un grupo del movimiento Túpac Amaru ${ }^{43}$, acto con el que se termina de desbaratar al MRTA. Es una figura creada por el artista con antelación para ser usada en su obra Try again, otra de sus reinterpretaciones históricas. ${ }^{44}$

Casi escondido, en un tercer plano como espectando de lejos fuera de escena, el teniente coronel boliviano Andrés Selich, de quien solo se percibe su cabeza. Su inclusión se debe a que dicho oficial fue el que entierra, clandestinamente, al Che Guevara ${ }^{45}$ aquel 11 de octubre de 1967 en Vallegrande, Bolivia, luego de haber sido exhibido al público.

A fin de reiterar que el país no se pertenece a sí mismo, el sombrero de la mano de Pizarro ha desaparecido para colocar en su lugar El Perucito, cojín elaborado por el artista peruano Juan Javier Salazar, empleando como modelo el mapa del Perú. Salazar en una entrevista

43 Después de cuatro meses de interminables y sordas conversaciones, la residencia es tomada, por un comando de 123 militares preparados para tal efecto, en el impresionante operativo Chavín de Huantar, denominado así por los tres túneles subterráneos, a semejanza de los habidos en la milenaria zona arqueológica de Ancash. El grupo de jóvenes emeterreístas estaba encabezado por el líder obrero Néstor Cerpa Cartolini quien, junto a sus demás compañeros, pierde la vida en el enfrentamiento armado.

44 Acrílico sobre tela del año 2002; mide 150 x $120 \mathrm{~cm}$. Se basa en el óleo La capitulación de Ayacucho del pintor Daniel Hernández, obra encargada por el gobierno de Augusto B. Leguía como parte de los festejos del centenario de la batalla de Ayacucho; es finalizada en 1924.

45 Ernesto "Che" Guevara, junto a algunos de sus compañeros, es tomado prisionero; trasladado al pueblo de La Higuera y encerrado en la escuelita de la localidad, es acribillado, para hacer creer a la opinión pública que había muerto en combate. El cadáver es trasladado en helicóptero a Vallegrande donde se expone públicamente; antes de enterrarlo le cortaron las manos. Después de una larga discusión es enterrado de manera clandestina por el teniente coronel Andrés Selich. El cuerpo es exhumado en 1997 y traslado a La Habana. 
afirma que esta obra es arte en serie para alcanzar mayor público teniendo como asunto el "tema patriótico de estado y geografía..." ${ }^{46}$ Si se observa con detenimiento parece, además, aquel precioso felino de la amazonía, el otorongo por la tela que lo envuelve con sugerente manchas y la cola. Es, asimismo, el mapa del Perú y la cola no es otra cosa que el mapa de Chile. Ahora bien, Pizarro tiene al Perú de cabeza sostenido por la larga franja del país sureño, enemigo ancestral que ocasiona el segundo trauma de la historia peruana cuando en el siglo XIX, a raíz de la Guerra del Pacífico, el Perú pierde gran parte de su territorio nacional donde se encontraban las riquezas del guano y salitre, en esos momentos dos recursos económicos de gran trascendencia. Resulta coherente esta actitud si se traslada al momento actual donde los capitales chilenos han invadido la economía nacional. ${ }^{47}$

Destaca del conjunto, dividiendo la escena de la izquierda con la de la derecha, la figura del Papa Benedicto XVI riendo quien, ahora, en vez de usar el agua bendita del cura Valverde, emplea como cabeza trofeo, la cabeza del Che Guevara para exorcisar, "alusión evidente al mito de

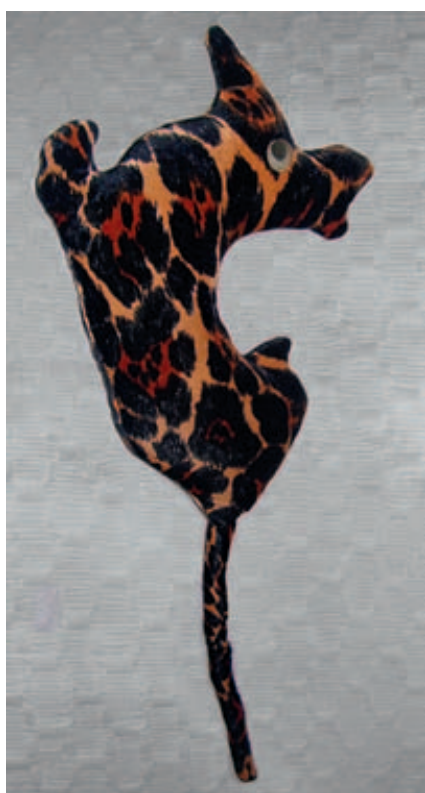

El Perucito. Juan Javier Salazar. Cojín. Inkarri: el inka-rey decapitado cuyo cuerpo se regenera bajo la tierra a la espera del momento propicio para volver a la superficie y restaurar el tiempo interrumpido de los indígenas." ${ }^{48}$ La foto del Che, difundida por la prensa boliviana a raíz de su muerte, ${ }^{49}$ en esta obra es un elemento de profundo significado político para América latina que ve en la figura del líder argentino la posibilidad del tan ansiado cambio político, social y económico, ahora convertido en utopía.

Velaochaga otorga al Inca Atahualpa mayor dignidad que aquella planteada en la obra en la cual se basa. Por una parte desaparece la cadena de la muñeca; la cambia por una pulsera, es decir rompe el símbolo de la esclavitud. Pero lo significativo es el lujoso manto, sobre el cual reposa, decorado con tocapos que, según el color varían en la dirección. Es necesario recordar que el tocapu ${ }^{50}$ es una clave, una llave, un sistema de escritura como ideograma, aún no decodificado de la cultura inca. Representados siempre en diagonal, se les ve en los unkus de la elite inca, en los óleos que encarnan la dinastía incaica, así como en algunos keros de madera durante toda la colonia.

El candelabro parado del óleo de Montero, Velaochaga lo reemplaza por un perro echado a los pies del lecho mortuorio de Atahualpa, imagen reciclada del cuadro Las meninas

46 Castro 2008 [En línea]

47 Algunos capitales son de carácter golondrinos, con bancos (Banco del Trabajo) que cobran tasas que fluctúan entre el 150 al $200 \%$ de interés, o con centros comerciales (Jockey Plaza) erigidos con estructuras desarmables, en los cuales la mercadería es recibida a consignación para ser pagada a noventa días gracias a empresarios chilenos que en su permanente ir y venir entre su país de origen y el de su inversión económica, contratan con salarios ínfimos a empleados peruanos. También hay inversiones en energía (Electrosur), mineras, puertos, entre otras.

48 Buntinx 2007.

49 Esta fotografía está reproducida en el libro de Paco Ignacio Taibo, biógrafo del Che Guevara.

50 Federico Kauffman Doig señala al respecto: “Los tocapos eran recuadros en sucesión, con diseños variables de rectángulo en rectángulo y que, yuxtapuestos, acaso podrían expresar o simbolizar una palabra o concepto dado. (...) William Burns ha desplegado notables esfuerzos para descifrar los tocapos; postula que se trataría de una escritura fonética en la que se representan las 10 principales consonantes. También los han estudiado Victoria de la Jara y Thomas Barthel." En Tauro del Pino 2001:2567. 
de Diego Velázquez. ${ }^{51}$ El artista lo hace de manera conciente, pues el perro en el mundo andino es el encargado de acompañar, orientar en el buen camino y cuidar a la persona fallecida para cruzar el río que la lleva al otro mundo, tarea que debe cumplir con la máxima autoridad Inca.

Esta parte del cuadro es cerrada en el ángulo inferior, cuando en un tamaño excesivamente grande en relación al entorno, un rostro en tres cuartos, en penumbras, observa con detenimiento hacia afuera, como invitando a involucrarse. Es "el autorretrato del artífice en un violento primer plano, interpelando al espectador desde los brillos de su mirada." 52 Velaochaga se toma la libertad de agregar este elemento no planteado en el original, como una manera de posesionarse de la obra. Este recurso de poner el autorretrato en uno de los ángulos sin formar parte directa del contenido, ya lo había empleado el francés Jean Charlot ${ }^{53}$ cuando en la capital mexicana pinta el mural Masacre de Tenochtitlán $;^{54}$ allí se ve a Charlot con la paleta y los pinceles, acompañado de Diego Rivera como "aprobando" la obra y de Fernando Leal quien mira de frente el mural de su factura, ${ }^{55}$ emplazado al frente del de Charlot, a modo de una respuesta pictórica contemporánea.

Ahora vamos a la izquierda de la composición con 18 individuos. El artista retira a algunos para reemplazarlos por nuevos, eso sí, manteniendo la misma estructura que la escena original. En primera instancia adelanta al soldado hispano para cambiarlo por un acusador comando norteamericano junto al Papa, figura no extraña en la historia peruana si se recuerda que en el impresionante operativo Chavín de Huantar, entre los 123 militares que participaron, había soldados traídos para tal efecto desde los Estados Unidos.

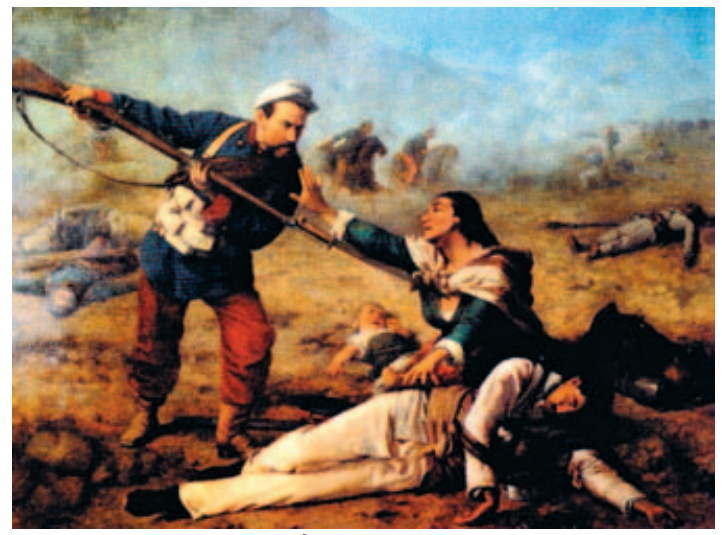

El Repase. Ramón Muñiz. Óleo sobre tela. Museo del Real Felipe.

A los pies del Papa la coya suicida, ahora acompañada de otra mujer que levanta la mano para impedir el exorcismo de Benedicto XVI. Esta vez se trata del cuadro decimonónico de Ramón Muñiz titulado El repase, óleo que narra el momento cuando una soldadera defiende el cuerpo de su marido para que no sea atravesado por la bayoneta calada de un soldado chileno durante la invasión de Chorrillos en enero de 1881, dentro de la ya comentada Guerra del Pacífico. Por segunda vez el problema con Chile, ahora referido a un acontecimiento anterior que también significó un asunto económico. Es interesante observar que el cuerpo de la coya caída está señalado por su propia silueta, tal como en la actualidad lo hace la policía en la escena de un crimen. Hay más. En las sombras del piso junto a ella, se perfila, en un suave color crema, el mapa de América del Sur que continúa su geografía hacia el centro y norte gracias al rebozo. Con este detalle Velaochaga convierte su obra en un asunto continental, la presencia militar norteamericana en diferentes países y regiones, ya insinuada con el comando.

51 Sevilla 1599-Madrid 1660. Uno de los más importantes pintores españoles. Las meninas es una de sus últimas y más trascendente de sus obras.

52 Buntinx 2007.

53 Nace en París en 1898. Llega al puerto de Veracruz, México en 1921. Fallece en Hawai en 1979.

54 Fresco pintado entre 1921 y 1922 en el antiguo Colegio de San Ildefonso, México D.F.

55 Titulado Fiesta del Señor de Chalma, fue elaborado, entre 1922 y 1923, en la técnica de la encaústica sobre muro. 
A la espalda de la citada Adelita, el cuerpo de otra coya ha sido cambiado por el detalle del tronco desnudo de un revolucionario mexicano caído, extraído del mural La trinchera de José Clemente Orozco considerada una obra maestra de la pintura mural. Este asunto, por su crudeza, exacerba el drama relatado.

El especial aprecio que Marcel Velaochaga siente hacia el pintor y grabador piurano Félix Rebolledo ${ }^{56}$ a quien le había dedicado su obra La mesa de trabajo de Félix Rebolledo, lo expresa nuevamente aquí. Es necesario recordar que Rebolledo con un quehacer artístico comprometido con lo social, llevaba dos años encerrado en San Juan de Lurigancho acusado de terrorismo, mientras el juicio continuaba; en junio de 1986 es una de las víctimas de la matanza de los penales habida Lima. En el cuadro de nuestro análisis el homenaje a Rebolledo es hecho a través de una importante xilografía, la aguerrida Toribia Flores de Cutipa; camina hacia donde se encuentra el Inca, con la misma actitud de la figura que reemplaza en el original a la cual un soldado intenta detener; uno de los niños es cambiado por una paleta de pintor, sutil modificación convertida en el tributo de un artista hacia otro.

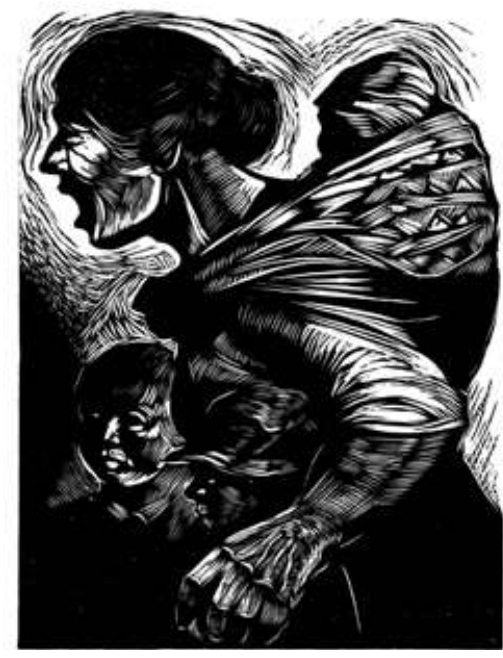

Toribia Flores de Cutipa. Félix Rebolledo. Grabado.

Las otras dos coyas, asimismo, son alteradas; la primera por una indígena que sujeta el brazo de uno de los militares; ella resalta del conjunto al ser presentada en blanco y negro en medio de un ambiente colorido; es una fotografía tomada de la etapa del terrorismo. Al igual que en el original de Montero, la segunda mujer reclama indignada a uno de los soldado el cadáver del Inca para enterrarlo según el rito apropiado. Velaochaga en su reciclaje extrae la imagen del dibujo Entierro de los condesuyos, el cual forma parte del "Capítulo de los Entierros" de la Nueva crónica y buen gobierno, obra de gran trascendencia etnográfica y literaria finalizada aproximadamente en 1615 por el cronista peruano Guaman Poma de Ayala $;{ }^{57}$ esta importante denuncia escrita, enfatizada con dibujos, fue enviada al rey Felipe III de España, pero nunca llegó a su destinatario por ser, arbitrariamente, desviada a una biblioteca. Ahora bien, en este caso la anciana representa a una de las tantas mujeres que exige los cuerpos de sus hijos y maridos desparecidos en la década de 1980.

A ellas se le acoplan otras dos mujeres: una india de Puno conocidas por su firmeza ante el trabajo, belicosidad y no permitir atropellos, y una militante senderista marchando acompañada con la bandera roja; está vestida con la típica camisa roja y la boina usada por ellas en los desfiles de alabanza al camarada Gonzalo o en las obras de teatro que representaban sobre la guerra popular en los interiores de los penales limeños hasta por lo menos 1991, cuando los tenían controlados.

El hermoso niño inca esta vez es replanteado por un humilde muchachito mulato mal vestido, quien con la misma desesperanza, dentro del espectáculo de muerte y destrucción ante sus ojos, mira el suelo, frente a un futuro incierto para él y el Perú, un país multiétnico

56 Piura 1944 - Lima 1986. Luego de egresar de la Escuela Nacional de Bellas Artes, viaja a París para perfeccionarse. Allí, en mayo de 1968, toma conciencia política y comprende que su arte debe estar al servicio de lo social. A su regreso al Perú se integra como docente a su alma mater, pero por sus planteamientos ideológicos es denunciado y encarcelado. Fallece en el motín de los penales el 19 de junio.

57 Nace en San Cristóbal de Suntuntu en el siglo XVI y fallece en Lima, se estima que en 1615. Cronista indígena hijo de señor principal. Viajó durante veinte o treinta años recogiendo información. Nueva crónica y buen gobierno es "un extenso memorial al rey de España sobre la situación en los Andes, su historia y costumbres, y recomendaciones para mejorar su gobierno." Tauro del Pino 2001:1106. 


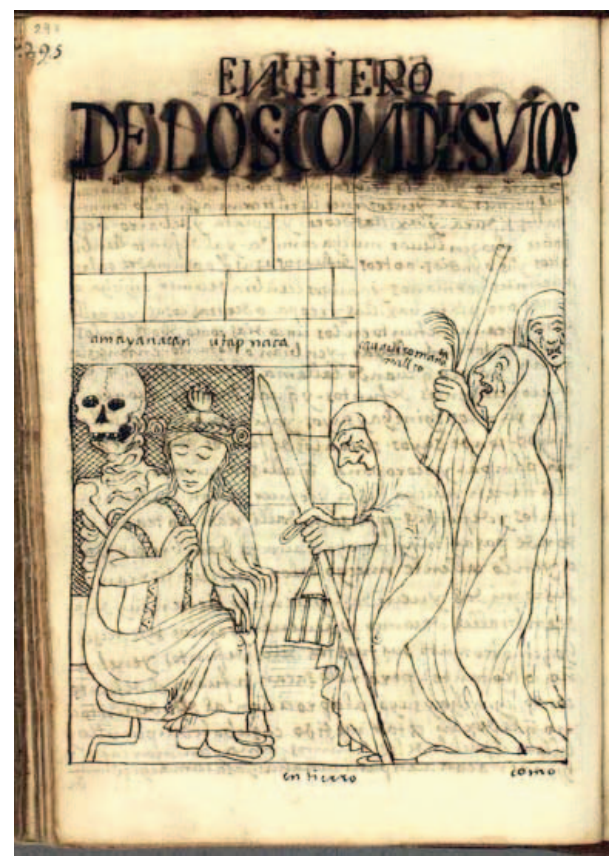

Entierro de los Condesuyos. Guaman Poma de Ayala. Dibujo. Siglo XVII.

donde las diferencias internas no terminan de solucionarse. Esa multietnicidad está expuesta a través de un pueblo formado por blancos, indios, mestizos y un negro personificado en un rostro de perfil, sugerido en el antebrazo de uno de los soldados.

Como espectador mudo de esta escenografía se encuentra, al fondo, una figura masculina perfilada en negro, vestida con capa y sombrero de ala ancha que reemplaza el retrato de Montero, imagen proveniente del cuadro El pintor de la capa negra ${ }^{58}$ elaborado por el Equipo Crónica ${ }^{59}$, colectivo valenciano, "sobre la pauta de un logotipo para la comercialización inglesa de vinos ibéricos ${ }^{60 "}$. El crítico Gustavo Buntinx estima que el gran sombrero de la enigmática figura coincide con aquel sostenido por Pizarro en el lienzo decimonónico de Montero ${ }^{61}$.

Recapitulando. Para convertir Los funerales de Atahualpa en un cuadro histórico contemporáneo, es decir, en cierto sentido "actualizarlo", Velaochaga recicló elementos creados por diez artistas que le antecedieron, sumando un total de cinco peruanos ${ }^{62}$ y seis extranjeros, ${ }^{63}$ sin mencionar a los fotógrafos que le facilitaron los retratos de varios actores de la época del genocidio peruano, paseándose de esta manera por la historia del arte como gran conocedor para poder elegir imágenes puntuales, que debían estar relacionadas con la narración; esto es, sin tomar en cuenta barreras cronológicas, estilísticas ni de disciplinas como la pintura, la fotografía, el grabado y la escultura. Del siglo XVII hizo suyo un dibujo de Guaman Poma seleccionado de un libro de denuncia que no cumplió su finalidad; de Rembrandt extrajo al observador científico que estudia la disección de un cadáver; de Velázquez se prestó un perro, animal imprescindible para el nuevo planteamiento, pues serviría de conductor al más allá al Inca Atahualpa para que llegara a su destino sin inconvenientes y de esta manera asegurar su retorno como un Inkarri. Del XIX se presta lo más importante, el cuadro de Luis Montero que le entregaría la inspiración así como las soluciones plásticas de composición y escenografía; de fines de la misma centuria otro español Muñiz, esta vez radicado en Lima, con una tela de denuncia hacia el comportamiento de las tropas chilenas cuando invaden Lima con la figura de la rabona, imagen aguerrida de la mujer que sigue a su marido y lo defiende bajo cualquier precio. Del siglo XX no pudo ignorar la influencia del muralismo mexicano del cual se apropió a través de Orozco con uno de los cuerpos caídos en una trinchera de la revolución. Le fue imposible pasar por alto el trabajo de Lichtenstein con el arte pop en la imagen de

58 Acrílico sobre lienzo; data de 1975 y mide 150 x $120 \mathrm{~cm}$. Pertenece a una colección particular de Valencia.

59 Grupo de pintores españoles conformado por Rafael Solber, Manolo Valdés y Juan Antonio Toledo. Está activo entre 1963 y 1981 cuando fallece Solber. Cultivó una pintura figurativa dentro del pop, analizando críticamente la situación política de España y la historia del arte. Se inspiró en obras clásicas como Las meninas de Velásquez y el Guernica de Picasso. Equipo Crónica. [En línea]

60 Buntinx 2007.

61 Buntinx 2007.

62 Guamán Poma de Ayala, Luis Montero, Félix Rebolledo, Juan Javier Salazar y el mismo artista, Marcel Velaochaga.

63 Diego Velázquez, Rembrandt, Ramón Muñiz, José Clemente Orozco, Roy Lichtenstein, Equipo Crónica. 
la llorosa gringa. La admiración a Rebolledo por su actuar artístico y político, la expresa a través de la feroz Cutipa, mujer del pueblo metamorfoseada en pintora; de los valencianos que integran el Equipo Crónica la silueta negra enigmática. Del siglo XXI emplea un trabajo de Salazar, el mapa del Perú convertido en un otorongo cautivo, elemento estupendo para ratificar el problema de la globalización; de su propio ingenio para rearmar la nueva idea, usa una de sus figuras, el espeluznante hombre con cabeza pétrea creado en base a las cabezas clavas Chavín elaboradas antes de nuestra era, expresando de esta manera el poderío de uno de los horizontes culturales ${ }^{64}$ habidos en el antiguo Perú, con un sistema capaz de controlar la política a lo largo y ancho del país gracias a una ideología religiosa fuerte apoyada por una elite militar poderosa.

La gran cantidad de códigos emitidos a través de nuevas imágenes encargadas de reemplazar a las anteriores, complican la lectura del cuadro para aquel que no conozca al detalle y en íconos la historia actual del Perú, hecho por el cual la obra se convierte en algo enigmático, alejado del espectador. Como si esto no fuera poco, Velaochaga no respeta el número de personas planteadas por Montero (31); lo cambia a 33 de manera sutil, casi imperceptible, al introducir tres nuevos personajes que no intervienen para nada en la estructura compositiva y por ende pasan desapercibidos numéricamente hablando. 33, la edad de Cristo cuando fue crucificado, significa, asimismo, el inicio de una nueva etapa. Para el Perú es el año en el cual el Inca Atahualpa es asesinado (1533) y probablemente su edad pues, si bien es cierto se desconoce el año de su nacimiento, se estima que éste fue a inicios del 1500 .

El más importante y fácil de percibir de los nuevos integrantes es el Che Guevara al centro mismo de la composición, donde recae toda la intensidad luminosa en blancos sobre intenso fondo rojo andino y amarillo fosforescente, convirtiéndolo, junto al Papa, en la figura más trascendente de la obra. Como es sabido, en el Perú antiguo las cabezas trofeos contienen un profundo significado, costumbre mantenida hasta el siglo XIX por los jíbaros localizados en la selva norte. Obtenida en una batalla cuerpo a cuerpo, la cabeza del vencido es llevada por el vencedor no solo para demostrar su triunfo ante los demás, sino para adjudicarse los atributos de valor, calidad, ferocidad, es decir una alimentación mítica, en cierto sentido una simbólica antropofagia ritual. ¿Es acaso éste un mensaje sutil de la mencionada antropofagia? o ise intenta enfatizar la muerte física del enemigo que sigue presente, cada día con mayor fuerza y por ende su martirio resultó infructuoso?

Los otros dos personajes carecen de tan alta relevancia. Es más, pasan desapercibidos. Uno de ellos, a la derecha, está oculto detrás del teniente coronel boliviano Selich; sólo se esboza su rostro marcado con manchas negras sobre fondo rojo, insinuando con fineza los anteojos ahumados y el bigote de alguien que a simple vista recuerda a un miembro de la policía de investigaciones, aquellos que nunca gustan mostrar sus ojos, pues son incapaces de sostener la mirada. Con respecto al otro individuo, emplazado a la izquierda, ya hemos comentado en un párrafo anterior; es el negro sugerido de perfil en la manga de uno de los soldados.

Dentro de este conteo no consideramos el retrato de Velaochaga (que para algunos pasaría a ser el integrante número 34), por estar a modo de firma, sin integrarse a la composición, en un primer plano desplazado en el ángulo inferior derecho. Asimismo, si bien es el artista, no forma parte trascendental de la historia política contemporánea, por lo mismo que él se coloca como un segmento del enmarcado negro.

64 Se entiende por horizonte cultural el alcance habido en un mismo grado de desarrollo y homogeneidad en todas las culturas o sociedades dentro de un espacio geográfico determinado. En el arte esto estaría expresado en el manejo de un mismo tipo de iconografía visualizada en la cerámica o en los tejidos. Son tres los horizontes culturales del antiguo Perú. Primer Horizonte (1800-500 a.C.) con el centro ceremonial de Chavín de Huantar como el lugar de peregrinación más importante. Horizonte Medio (siglo VI-XI d.C.) con las culturas Tiawanaco-Wari-Sicán. Horizonte Tardío (siglo XVI a 1532 d.C.) con la cultura Inca. 
Entre todas la personas allí presente sólo son identificadas retratísticamente cinco: de la etapa de la conquista el Inca Atahualpa y Francisco Pizarro quienes marcaron el fin de un periodo e inicio de otro. De la segunda mitad del siglo XX el Che Guevara y Abimael Guzmán, los dos, desde sus planteamientos ideológicos, estuvieron interesados en cambiar la estructura del Estado. El siglo XXI, es decir nuestro pasado inmediato, se presenta con el Papa Benedicto XVI reconocido como estratega que intenta retornar a políticas eclesiásticas anteriores al Concilio Vaticanum II.

En cuanto al colorido, Velaochaga elabora una nueva propuesta. Frente al original de Montero con "ocres y sienas en el lado izquierdo y el contraste de verde y rojo, en el lado derecho" 65 , lanza el predominio del rojo, color característico andino expresado sobre todo en la brillantez de la columna principal. Por otra parte, el "fino trabajo de veladuras y modelado suave a favor de la línea", tradicional en la escuela florentina ${ }^{66}$ es trastocado con manchas que hacen perder el preciosismo característico del XIX, no necesario en el XXI.

A diferencia de Montero que excluye al indio, Velaochaga lo hace formar parte de la obra en un pueblo conformado por indígenas, mestizos, negros y mulatos reciclados de óleos, grabados y fotografías, estas últimas venidas de la etapa del terrorismo que tanta muerte y destrucción causó al país, rompiendo así con el ideal de belleza occidental para imponer otra sensibilidad lejana a la académica, propia de una época postmoderna donde todo es válido, excluyendo por ende la belleza, lo sublime, la luminosidad, la novedad y todos esos estereotipos que eran requeridos para que una obra alcanzara el estatus de arte.

Es imposible pasar por alto el tratamiento dado a la arquitectura en este cuadro. Aquella pétrea y robusta del óleo de Montero, ahora se la percibe ruinosa, en adobes irregulares semi desestabilizados. La hornacina, transformada en vano de una puerta, permite observar una habitación contigua en penumbras, depósito de adobes en mal estado. ¿Es acaso esta la imagen precaria que el artista quiere remitir al espectador acerca de la actual estructura del Perú?

Finalmente, resulta interesante la actitud de Velaochaga cuando determina compartir su obra. Para comprender esta idea es necesario regresar, por algunos instantes, al siglo XIX cuando Luis Montero, para pintar a Atahualpa utilizó el retrato postmortem de Tinajeros, pues su rostro tenía marcados rasgos indígenas. Marcel Velaochaga no quiso dejar fuera de su lienzo el detalle arequipeño, razón por la cual solicitó a su amigo, el pintor arequipeño Miguel Cordero Velasques, que viniera a Lima para pintar la figura de Atahualpa ${ }^{67}$.

Con esta obra Marcel Velaochaga pone sobre la mesa de debate que en pleno siglo XXI la historia de la conquista continúa vigente cuando, otra vez, clero y milicia convertidos en las fuerzas del orden, controlan al pueblo sumido en la indigencia o esclavizado a través de las tarjetas de crédito gracias a un maquiavélico sistema de orden mundial.

65 Castrillón 1994:92.

66 Castrillón 1994:93.

67 Velaochaga 2010. Entrevista. 


\section{Bibliografía}

\section{Amigo, Roberto}

2001 Tras un inca. Los Funerales de Atahualpa de Luis Montero en Buenos Aires. Argentina, Fundación para la Investigación del Arte Argentino - Telefónica.

\section{Buntinx, Gustavo}

2007 Lo impuro y lo contaminado: pulsiones (neo) barrocas en las rutas de MicroMuseo. Lima. Tarjeta para la Bienal de Sao Paulo - Valencia 2007. Encuentro Entre Dos Mares.

\section{Castrillón, Alfonso}

1994 "De los ocres, verde y rojos." En Varios Autores. Pintura Piurana. Lima, Banco Regional del Norte, pp. 92-93.

\section{Castro, Jimmy}

2008 "Juan Javier Salazar. Nuestro arte tiene mente colonialista." Entrevista. Accesible en internet www.agenciaperu.com/ cultura [Consulta agosto 3 de 2009, 11:36 horas]

Enciclopedia Salvat. Diccionario

1984 México, Salvat Mexicana de Ediciones.

\section{Equipo Crónica}

2009 Accesible en internet http:// es.wikipedia.org [Consulta agosto 12, 10:32 horas]

\section{García Márquez, Gabriel}

2002 Vivir para contarla. Colombia, Editorial Norma.

Garvich, Javier

2007 Bienal de Valencia. Accesible en internet www.blogalaxia.com/tags/ marcel+velaochaga [Consulta agosto 3 de 2009, 11:27 horas]

Lavarello de Velaochaga, Gabriela

2009 Artistas plásticos en el Perú. Siglos XVI, XVII, XVIII, XIX y XX. Lima, Editorial Pacasmayo.

\section{Lori Berenson}

2009 Accesible en internet www.rpp.com.pe, mayo 6. [Consulta agosto 12 de 2009 , 10:15 horas]

\section{Macera, Pablo}

(s/f) Historia del Perú. La Colonia. Lima, Editorial Bruño.

Majluf Brahim, Natalia

2004 "El rostro del Inca. Raza y representación en Los funerales de Atahualpa de Luis Montero". En Illapa, $\mathrm{N}^{\circ}$ 1. Lima, IIMA, pp. 11-28.

Marcel Velaochaga Accesible en internet www.velaochaga. com [Consulta agosto 3 de 2009, 11:37 horas].

Marzal, Manuel

1990 Claves de Interpretación para el Catolicismo Popular Peruano. Lima, Pontificia Universidad Católica del Perú.

Silva Santiesteban, Fernando

1987 "Cajamarca, de Asentamiento Preincaico a Villa Colonial (Siglos XVI al XVII)." En Plaza Mayor No 25, Lima, abril, pp. 4-11.

Szabó, Júlia

1988 Painting in Nineteenth Century Hungary. Traducción: Llona Potay. Corvina, Kiadó, Békécsaba.

\section{Tauro del Pino, Alberto}

2001 Enciclopedia Ilustrada del Perú. Lima, PeisaEl Comercio.

Velaochaga, Marcel Artista plástico. Entrevista realizada en Barranco, Lima, el 7 de octubre de 2010.

Veliz, Alexa y María Isabel Torres De "Norah" a "Miriam". Las mujeres de Abimael Guzmán. Accesible en internet www.agenciaperu.com.pe/reportes/2004/ nov/abimael.htm [Consulta agosto $26 \mathrm{de}$ 2009, 09:45 horas]

Yuyanapaq. Para recordar 1980-2000. Relato visual del conflicto armado interno en el Perú (2003). Lima, Fondo Editorial de la Pontificia Universidad Católica del Perú. 